\title{
$\mathrm{H}_{2} \mathrm{O}_{2}$ biosensor consisted
}

\section{of hemoglobin-DNA conjugate on nanoporous gold thin film electrode with electrochemical signal enhancement}

\author{
Jinhee Jo ${ }^{1}$, Jinho Yoon ${ }^{1}$, Taek Lee ${ }^{1,2}$, Hyeon-Yeol Cho ${ }^{1,3}$, Ji-Young Lee ${ }^{1}$ and Jeong-Woo Choi ${ }^{{ }^{*}}$
}

\begin{abstract}
In this research, we developed electrochemical biosensor which was composed of hemoglobin ( $\mathrm{Hb}$ )-DNA conjugate on nanoporous gold thin film (NPGF) for hydrogen peroxide $\left(\mathrm{H}_{2} \mathrm{O}_{2}\right)$ detection. For the first time, $\mathrm{Hb}$ and DNA was conjugated as a sensing platform for uniform orientation of $\mathrm{Hb}$ on electrode. The newly developed $\mathrm{Hb}$-DNA conjugate was designed to prevent $\mathrm{Hb}$ from aggregation on electrode. DNA hybridization of $\mathrm{Hb}-\mathrm{DNA}$ conjugate and complementary DNA (cDNA) on NPGF electrode induced uniformly assembled biosensor. Furthermore, NPGF electrode fabrication method was introduced to the increment of the surface area. To confirm the conjugation of Hb-DNA conjugate, sodium dodecyl sulfate polyacrylamide gel electrophoresis (SDS-PAGE) and ultraviolet-visible spectroscopy (UV-VIS) were used. Formation of the NPGF electrode was verified by scanning electron microscope (SEM). Atomic force microscopy (AFM) was operated for the confirmation of Hb-DNA immobilization on electrode. The electrochemical property of fabricated electrode was investigated by cyclic voltammetry (CV). Also, $\mathrm{H}_{2} \mathrm{O}_{2}$ sensing performance of fabricated electrode was investigated by amperometric i-t curve technique. This sensor showed a wide linear range from 0.00025 to $5.00 \mathrm{mM}$ and a correlation coefficient of $R^{2}=0.9986$. The detection limit was $250 \mathrm{nM}$. Proposed biosensor can be utilized as a sensing platform for development of biosensor.
\end{abstract}

Keywords: Biosensor, DNA hybridization, Hemoglobin, Hydrogen peroxide, Nanoporous gold thin film

\section{Introduction}

Over the past decades, various researches for the development of biosensors have received the huge interests for biomedical and environmental applications. Several biomolecules such as protein and DNA have some advantages for the development of biosensors including fast response reaction and remarkable selectivity $[1,2]$. Particularly, metalloproteins have been evaluated as suitable materials for biosensors because of the direct redox properties and the fast electrochemical response [3-5]. Chen's group used glucose oxidase as metalloprotein

*Correspondence: jwchoi@sogang.ac.kr

${ }^{1}$ Department of Chemical and Biomolecular Engineering, Sogang University, 35 Baekbeom-ro (Sinsu-dong), Mapo-gu, Seoul 121-742, Republic of Korea

Full list of author information is available at the end of the article for detecting trichloroacetic acid for glucose detection [6]. Sun's group used myoglobin as metalloprotein for detecting trichloroacetic acid [7]. Also, our group especially developed various biosensors using metalloprotein [8-10].

Hydrogen peroxide $\left(\mathrm{H}_{2} \mathrm{O}_{2}\right)$ is widely known as unstable and reactive product in biological system which affected harmful effect to living cells. As a main by-product of enzymatic reactions, concentration of $\mathrm{H}_{2} \mathrm{O}_{2}$ is considered as a parameter for activity coefficient of physiological reactions [11]. Consequently, various types of biosensors have been developed to detect $\mathrm{H}_{2} \mathrm{O}_{2}[12,13]$. Kauffmann's group developed the $\mathrm{H}_{2} \mathrm{O}_{2}$ biosensor using enzyme horseradish peroxidase (HRP) entrapped in a polypyrrole electrode [14]. Luo's group fabricated $\mathrm{H}_{2} \mathrm{O}_{2}$ biosensor which was based on cytochrome c [15]. 
However, conventional biosensors had some limitations such as high detection limit and irregularly assembled biomolecules on the electrode which interrupted the accurate interaction between the target material and sensing molecule (Additional file 1: Table S1). To overcome these limitations, the expansion of surface area of the electrode and the uniform immobilization of the sensing molecule on the electrode could be expected as proper solution [16]. To expand the surface area of the electrode, the nanoporous gold thin film (NPGF) was widely used for electrode preparation [17]. The electrochemical signal of biomolecules could be enhanced due to the immobilization of more sensing molecules on the electrode by the surface expansion and the enhanced electron transfer rate [18].

DNA has the unique property that single strand DNA can form the hybridized double strand DNA with high selectivity by introduction of complementary DNA (cDNA). Thus, DNA has been widely used to fabricate the self-assembled structure precisely $[19,20]$. This unique property of DNA can be applied to fabricate the well orientated biomolecule layer on the electrode. The NPGF electrode technique and uniform orientation via DNA hybridization showed synergy effect through electrochemical signal enhancement.

In this point of view, for the first time, an electrochemical biosensor composed of hemoglobin (Hb)-DNA conjugate on the NPGF electrode was developed to detect $\mathrm{H}_{2} \mathrm{O}_{2}$ with electrochemical signal enhancement and high selectivity. Newly developed Hb-DNA conjugate was used as a sensing platform. $\mathrm{Hb}$ and DNA were conjugated by sulfosuccinimidyl 4-cyclohexane-1-carboxylate (Sulfo-SMCC). Also, the electrodeposition technique was applied to fabricate the NPGF electrode for the expansion of the surface area of electrode. The thiol-modified cDNA was directly immobilized on the NPGF electrode by self-assembly of gold-thiol interaction. Then, as a biomolecular probe, Hb-DNA conjugate was immobilized on the electrode by DNA hybridization. $\mathrm{Hb}$ is the metalloprotein with four iron ions in its core which can detect $\mathrm{H}_{2} \mathrm{O}_{2}$ by the electrochemical reduction reaction with $\mathrm{H}_{2} \mathrm{O}_{2}$ accompanying the unique redox properties. Also, $\mathrm{Hb}$ can detect $\mathrm{H}_{2} \mathrm{O}_{2}$ by the electrochemical reduction reaction with $\mathrm{H}_{2} \mathrm{O}_{2}$. As $\mathrm{Hb}$ is one kind of heme proteins, it contains heme groups. Iron in the heme can undergo oxidation and reduction over a wide range of potentials around heme groups. Because of the redox property of heme proteins, they have the great potential to be applied for biosensors. The final goal of this research was uniform orientation of protein to avoid aggregation. Consequently, well orientated protein without aggregation was expected to show enhanced performance comparing conventional self-assembled sensors.

Fabrication of the NPGF electrode was investigated by scanning electron microscope (SEM) and atomic force microscopy (AFM). To confirm the fabrication of $\mathrm{Hb}$ DNA conjugate, sodium dodecyl sulfate polyacrylamide gel electrophoresis (SDS-PAGE) and ultraviolet-visible spectroscopy (UV-VIS) were used. Cyclic voltammetry (CV) was used for the electrochemical signal enhancement of fabricated biosensor. Also, immobilization of $\mathrm{Hb}-\mathrm{DNA}$ conjugate on the electrode was investigated by AFM. Finally, $\mathrm{H}_{2} \mathrm{O}_{2}$ sensing performance of fabricated biosensor was estimated by amperometric $\mathrm{i}-\mathrm{t}$ curve technique. Figure 1 showed the schematic diagram of fabricated Hb-DNA conjugate on the NPGF electrode via DNA hybridization with uniform orientation.

\section{Materials and methods}

\subsection{Materials}

Hemoglobin from bovine blood, gold chloride trihydrate $99.9 \%$ trace metals basis, L-ascorbic acid (AA), uric

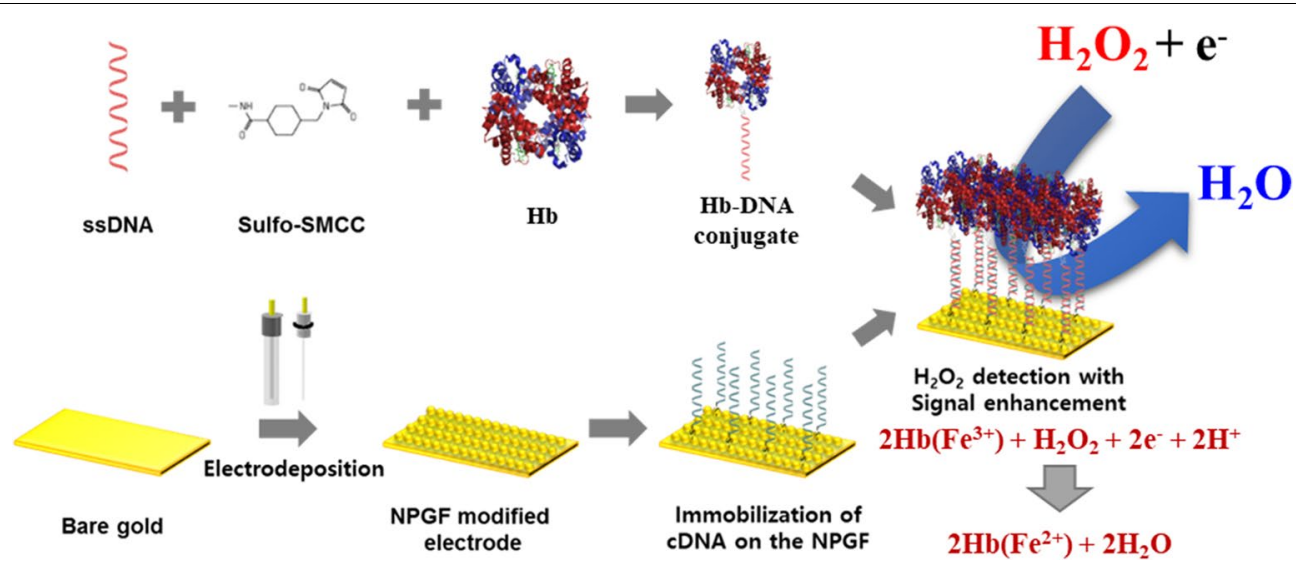

Fig. 1 The schematic diagram of Hb-DNA conjugate on the NPGF electrode 
acid (UA), sodium nitrite $\left(\mathrm{NaNO}_{2}\right)$, sodium bicarbonate $\left(\mathrm{NaHCO}_{3}\right)$ solution and human serum from human male AB plasma were purchased from Sigma-Aldrich (USA). Polyethylene glycol (PEG) was purchased from Yakuri Pure Chemicals Co. LTD. (Japan). To conjugate Single stranded DNA (ssDNA) to the amide end of hemoglobin, the 5 prime end of ssDNA (5'-ATAAAAAAAGCGCGG GGGTTCCGCG-3') was modified with a thiol group. The 5 prime end of cDNA (5'-AAAATAAAAACGCGC GGAACCCCCGCGC-3') was also modified with a thiol group to immobilize on the NPGF electrode. ssDNA and cDNA were synthesized by Bioneer (South Korea). SulfoSMCC, and Bond-Breaker ${ }^{\mathrm{TM}}$ tris(2-carboxyethyl)phosphine (TCEP) solution were purchased from Thermo Fisher Scientific (USA). Gold substrate was purchased from National Nanofab Center (South Korea). Precision Plus Protein ${ }^{\mathrm{TM}}$ Unstained Protein Standards was purchased from Bio-rad (USA). Ethyl alcohol anhydrous, sulfuric acid, and $\mathrm{H}_{2} \mathrm{O}_{2}$ solution were purchased from Daejung Chemical (South Korea).

\subsection{Fabrication of the NPGF electrode}

First of all, the electrodes were cleaned using a piranha solution $\left(\mathrm{H}_{2} \mathrm{SO}_{4}: \mathrm{H}_{2} \mathrm{O}_{2}, 8: 2 \mathrm{v} / \mathrm{v}\right)$ for $5 \mathrm{~min}$, then deionized water (DIW) was used to wash electrode, and $\mathrm{N}_{2}$ gas was used to dry the substrate. According to the strong oxidizing property of the piranha solution, it could remove organic materials while making the surface highly hydrophilic.

To fabricate uniformly electrodeposited NPGF electrode, $1 \mathrm{~mL}$ of $10 \mathrm{mM}$ gold chloride trihydrate aqueous solution and $4 \mathrm{~mL}$ of PEG aqueous solution $(20 \mu \mathrm{L}$ per $1 \mathrm{~mL}$ of DIW) were mixed. The three electrode system was utilized to fabricate the NPGF electrode by electrodeposition. Our three electrode system is composed as it follows, cleaned gold electrode was connected to working electrode, platinum wire was used as counter electrode and silver/silver chloride $(\mathrm{Ag} / \mathrm{AgCl})$ double-junction electrode was used as a reference electrode. And all of electrode supplies were purchased from $\mathrm{CH}$ Instruments (CHI). Under the room temperature, electrodeposition technique was performed at $-1.3 \mathrm{~V}$ for $30 \mathrm{~s}$ with multipotential steps technique using potentiostat (CHI-660A, CHI, USA). The formation of the surface was investigated by SEM (SUPRA 55VP, Carl Zeiss, Germany).

\subsection{Conjugation of ssDNA and $\mathrm{Hb}$}

To make Hb-DNA conjugate, Sulfo-SMCC was used as a crosslinker between $\mathrm{Hb}$ and ssDNA [21]. For preparation, ssDNA and Hb were dissolved in Tris-EDTA (TE) buffer at $10 \mu \mathrm{M}$ concentration each. To fabricate $\mathrm{Hb}$ ssDNA conjugate, $10 \mu \mathrm{L}$ of $1.0 \mathrm{M}$ dithiothreitol (DTT) was added to every $100 \mu \mathrm{L}$ of ssDNA solution. Then, the solution was incubated for $15 \mathrm{~min}$ at room temperature. Consumed DTT was removed using pure ethyl acetate. After the removal of consumed DTT, $10 \mu \mathrm{L}$ of SulfoSMCC $(10 \mathrm{mM})$ was added immediately, because free sulfhydryl group becomes unstable after the removal of DTT. The mixture was incubated for $2 \mathrm{~h}$ at $4{ }^{\circ} \mathrm{C}$. After incubation, $10 \mu \mathrm{M}$ of hemoglobin solution was added as the same volume ratio and was incubated for $6 \mathrm{~h}$ at $4{ }^{\circ} \mathrm{C}$. The thiol-modified ssDNA is reacted with Sulfo-SMCC. And then, the the amine group of $\mathrm{Hb}$ was added to thiolmodified ssDNA-Sulfo SMCC for form amide bond. Finally, Hb-SMCC-DNA conjugate was prepared [21].

\subsection{Immobilizing Hb-DNA conjugate on the NPGF}

As the gold-thiol interaction was much stronger than dithiol interaction, thiol modified cDNA was immobilized on the NPGF electrode uniformly by self-assembly $[22,23]$. As the DNA molecule has negative charge at $\mathrm{pH}$ 7.4, its repulsive force between DNA-DNA interactions induced uniform self-assembly on the gold substrate. $10 \mu \mathrm{M}$ of cDNA was dropped on the NPGF electrode sufficiently and kept in $4{ }^{\circ} \mathrm{C}$ for $6 \mathrm{~h}$. Then, $\mathrm{N}_{2}$ gas was used to dry the cDNA-immobilized NPGF electrode. Prepared Hb-DNA conjugate was immobilized on the electrode via DNA hybridization. To confirm the electrochemical signal enhancement of the proposed biosensor, only $\mathrm{Hb}$ immobilized electrode was prepared by the chemical linker 6-mercaptohexanoic acid (6-MHA) for comparison. To fabricate this, 6-MHA was immobilized on the electrode with self-assembly method for $3 \mathrm{~h}$ at $4{ }^{\circ} \mathrm{C}$. Then after $3 \mathrm{~h}, 6-\mathrm{MHA}$ solution was dried by $\mathrm{N}_{2}$ gas. Then, $\mathrm{Hb}$ was spread on to the electrode for another $3 \mathrm{~h}$ at $4{ }^{\circ} \mathrm{C}$ with self-assembly method.

\subsection{Electrochemical investigation of NPGF/CDNA/Hb-DNA conjugate biosensor}

The electrochemical property of NPGF/cDNA/Hb-DNA conjugate biosensor was analyzed using an electrochemical workstation. As the applied parameters for $\mathrm{CV}$, voltage range of $0.6 \mathrm{~V}$ to $-0.2 \mathrm{~V}, 50 \mathrm{mV} / \mathrm{s}$ scan rate and at $1 \times 10^{-5}(\mathrm{~A} / \mathrm{V})$ sensitivity were used. And phosphate buffered saline (PBS) was used as an electrochemical buffer [24]. After CV investigation, amperometric i-t curve technique was performed to investigate the performance in $\mathrm{H}_{2} \mathrm{O}_{2}$ detection. Parameters for amperometric $\mathrm{i}-\mathrm{t}$ investigation were $-0.3 \mathrm{~V}$ initial potential, $0.1 \mathrm{~s}$ sampling interval time and $2 \times 10^{-6}(\mathrm{~A} / \mathrm{V})$ sensitivity.

\section{Results and discussion}

\subsection{Verification of the NPGF electrode formation}

Figure 2 showed the SEM results of the bare gold electrode and fabricated NPGF electrode. In Fig. 2a, the flat gold substrate was shown accompanying around $10 \mathrm{~nm}$ 
a

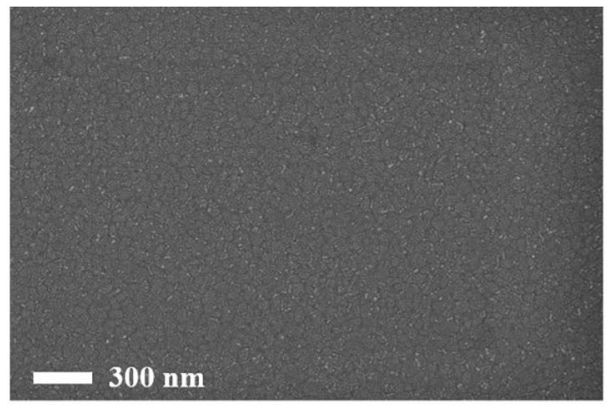

C

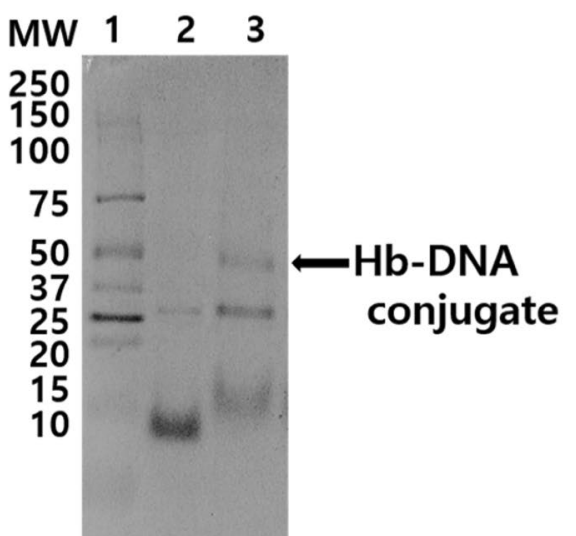

b

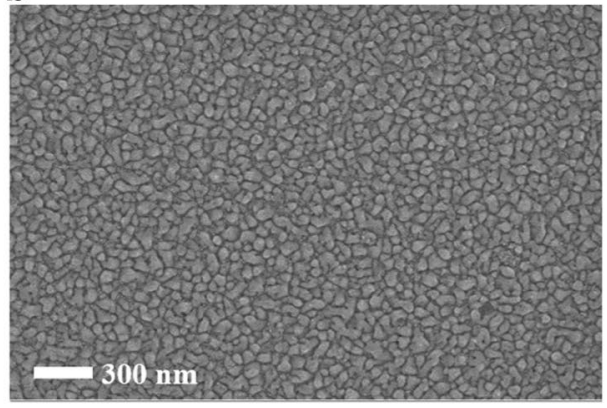

d

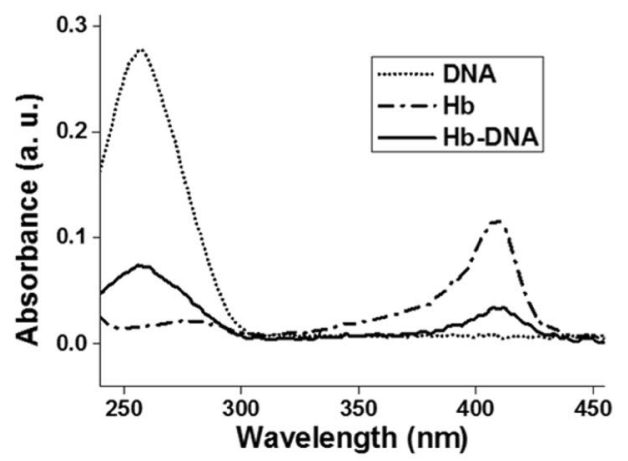

Fig. 2 SEM images of a bare gold; $\mathbf{b}$ NPGF electrode; c SDS-PAGE (lane 1 for protein ladder, lane 2 for $\mathrm{Hb}$, lane 3 for Hb-DNA conjugate); d UV-VIS results of $\mathrm{Hb}$-DNA conjugate

size of small clusters. By applying the $-1.3 \mathrm{~V}$ for $30 \mathrm{~s}$ on the bare gold electrode, gold nanoporous with diameter of $40.69 \mathrm{~nm}$ were uniformly deposited onto gold electrode in Fig. 2b and Additional file 1: Fig. S2. Through the NPGF electrode, surface extension of the substrate was investigated. Additional electrodeposition experiments were conducted to find optimized condition for the NPGF electrode. Additional file 1: Fig. S1 showed aggregation of gold nanoparticles with higher voltage or more time.

\subsection{Confirmation of Hb-DNA conjugate}

In Fig. 2c, protein ladder and $\mathrm{Hb}$ are shown in Lane 1 and Lane 2, respectively. The $\mathrm{Hb} / \mathrm{Sulfo}-\mathrm{SMCC} / \mathrm{ssDNA}$ conjugate is shown in Lane 3. In Lane 2, two bands (10 kDa for $\mathrm{Hb}, 25 \mathrm{kDa}$ for aggregated $\mathrm{Hb}$ ) were detected. In Lane 3, three bands (15 kDa for DNA, $25 \mathrm{kDa}$ for aggregated $\mathrm{Hb}$, and $40 \mathrm{kDa}$ for DNA-aggregated $\mathrm{Hb}$ conjugate) were found. Therefore, Hb-DNA conjugate was successfully fabricated.

Figure $2 \mathrm{~d}$ showed UV-VIS spectra of ssDNA, $\mathrm{Hb}$ and Hb-DNA conjugate. The ssDNA showed absorbance at $270 \mathrm{~nm}$ wavelength. This absorbance was attributed from the chromophoric groups in purine (adenine and guanine) and pyrimidine (cytosine and thymine) parts which are related to the electronic transition [25]. Also, $\mathrm{Hb}$ showed Soret absorption band of iron heme at $420 \mathrm{~nm}$ wavelength. This Soret peak could be shifted or disappeared if the $\mathrm{Hb}$ is denatured [26]. Consequently, the Hb-DNA conjugate showed absorbance at both of previous mentioned area (270 nm and $420 \mathrm{~nm}$ wavelength). Based on results of SDS-PAGE, Hb-DNA conjugate was confirmed at lane 3 showing $40 \mathrm{kDa}$ of molecular weight. And $\mathrm{Hb}$-DNA conjugate was also confirmed while having $\mathrm{Hb}$ and DNA UV-VIS peak at $270 \mathrm{~nm}, 420 \mathrm{~nm}$ respectively. We confirmed the successful fabrication of $\mathrm{Hb}$ DNA conjugate by using Sulfo-SMCC.

\subsection{Morphology investigation of the fabricated biosensor}

AFM was utilized to examine the surface of the fabricated biosensor. As shown in Fig. 3a, Hb with chemical linker, 6-MHA, was aggregated on the surface of bare gold electrode with $200 \mathrm{~nm}$ size. And the surface of $\mathrm{Hb}$ via 6-MHA linker also showed root mean square (RMS) roughness $6.331 \pm 1.293$. On the other hand, Hb via DNA hybridization was uniformly immobilized onto the bare gold 

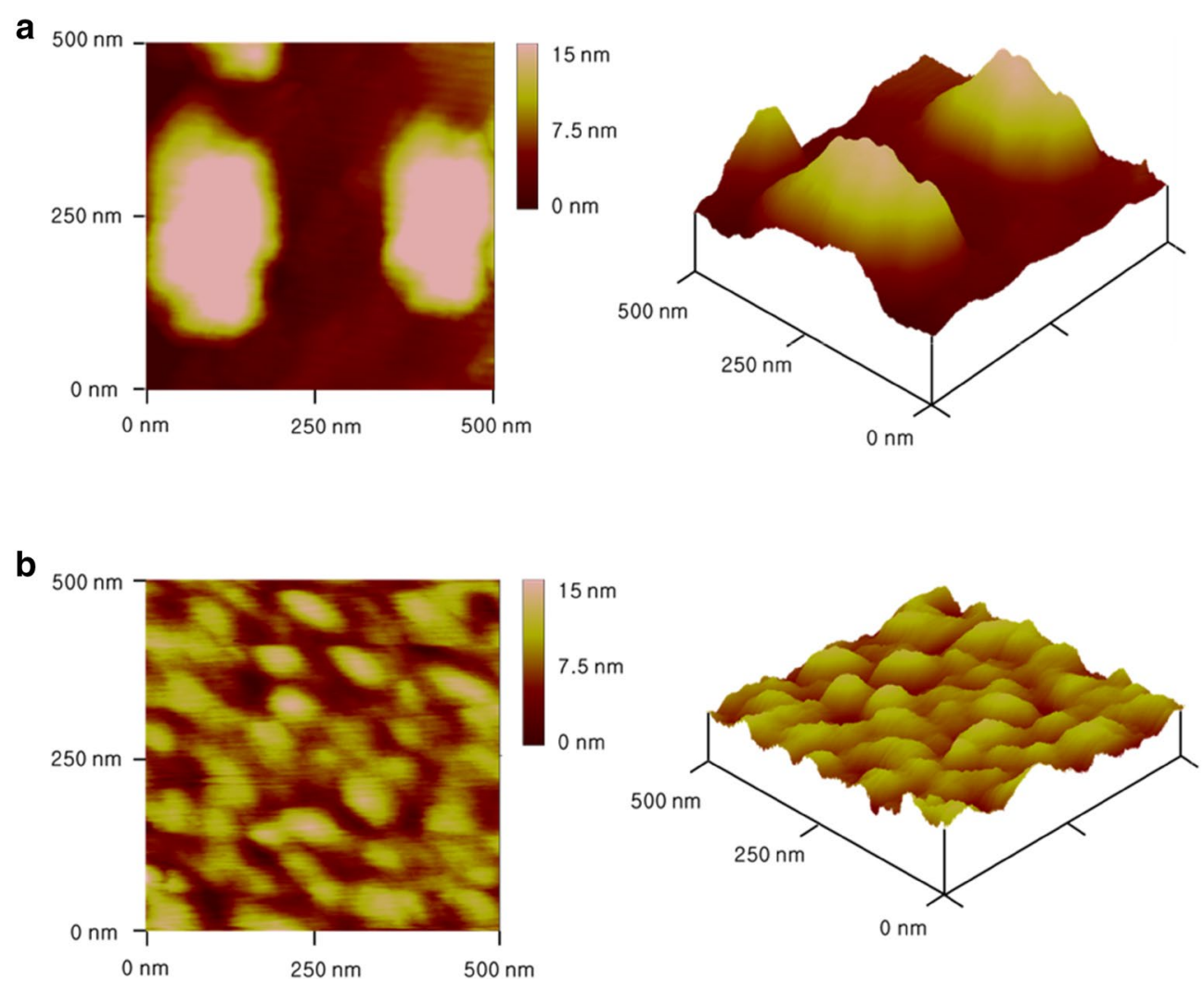

Fig. 3 AFM results of $\mathbf{a}$ aggregated $\mathrm{Hb} / 6-\mathrm{MHA} /$ gold electrode; $\mathbf{b} \mathrm{Hb} / \mathrm{DNA}$ hybridization/gold electrode

Table 1 Analysis of surface roughness

\begin{tabular}{lcc}
\hline & 6-MHA/Hb & DNA/Hb \\
\hline $\begin{array}{l}\text { Roughness average } \\
\text { (RA) (nm) }\end{array}$ & $5.687 \pm 1.189$ & $0.848 \pm 0.416$ \\
$\begin{array}{l}\text { RMS roughness } \\
\text { (Rq) (nm) }\end{array}$ & $6.331 \pm 1.293$ & $1.021 \pm 0.481$ \\
$\begin{array}{l}\text { Maximum roughness } \\
\text { (Rmax) (nm) }\end{array}$ & $17.803 \pm 3.488$ & $4.019 \pm 1.749$ \\
\hline
\end{tabular}

electrode without aggregation. We confirmed uniform immobilization through not only AFM data but also RMS roughness value. Consequently, RMS roughness showed $1.021 \pm 0.481$ which is diminished to one-sixth of previous RMS roughness of 6-MHA method [27, 28]. The 2D and 3D morphologies of the fabricated electrodes are shown in Fig. 3a, b, respectively. Chemically linked Hb showed six times higher roughness value than DNA-hybridization method (Table 1).

\subsection{Electrochemical investigation of the fabricated biosensor}

Figure 4a illustrated that the fabricated sensor showed signal enhancement comparing to bare gold electrode,
NPGF electrode, $\mathrm{Hb}$ on the NPGF by 6-MHA linker and $\mathrm{Hb}$ on the NPGF by DNA hybridization. The fabricated biosensor showed reduction peak at $0.20 \mathrm{~V}$. It also showed an oxidation peak at $0.0 \mathrm{~V}$. At reduction peak, $\mathrm{HbFeIII}$ reacted with $\mathrm{H}_{2} \mathrm{O}_{2}$ and electron to give HbFeII. On the other hand, HbFeII was decomposed as HbFeIII, electron and $\mathrm{H}_{2} \mathrm{O}_{2}$ at oxidation peak [29]. When comparing electrochemical signal between the NPGF and the bare gold, signal enhancement of the NPGF electrode was verified because of the expanded surface area by compactly deposited gold nanoparticles on the gold electrode. Figure 4a showed that the signal by DNA hybridization was improved comparing to the conventional sensor which is composed of 6-MHA which is known as chemical linker. Especially in the range of 0.10 to $0.20 \mathrm{~V}$, the DNA hybridization sensor showed ten times higher reduction peak than the 6-MHA chemical linker sensor. As shown in Fig. 4a, the electrochemical signal was enhanced by the NPGF electrode and DNA hybridization. Additional file 1: Fig. S3 showed stability test with $\mathrm{CV}$ and showed storage stability after 25 cycles.

Fourier-transform infrared spectroscopy (FT-IR) analysis was also conducted to verify whether $\mathrm{Hb}$ was 

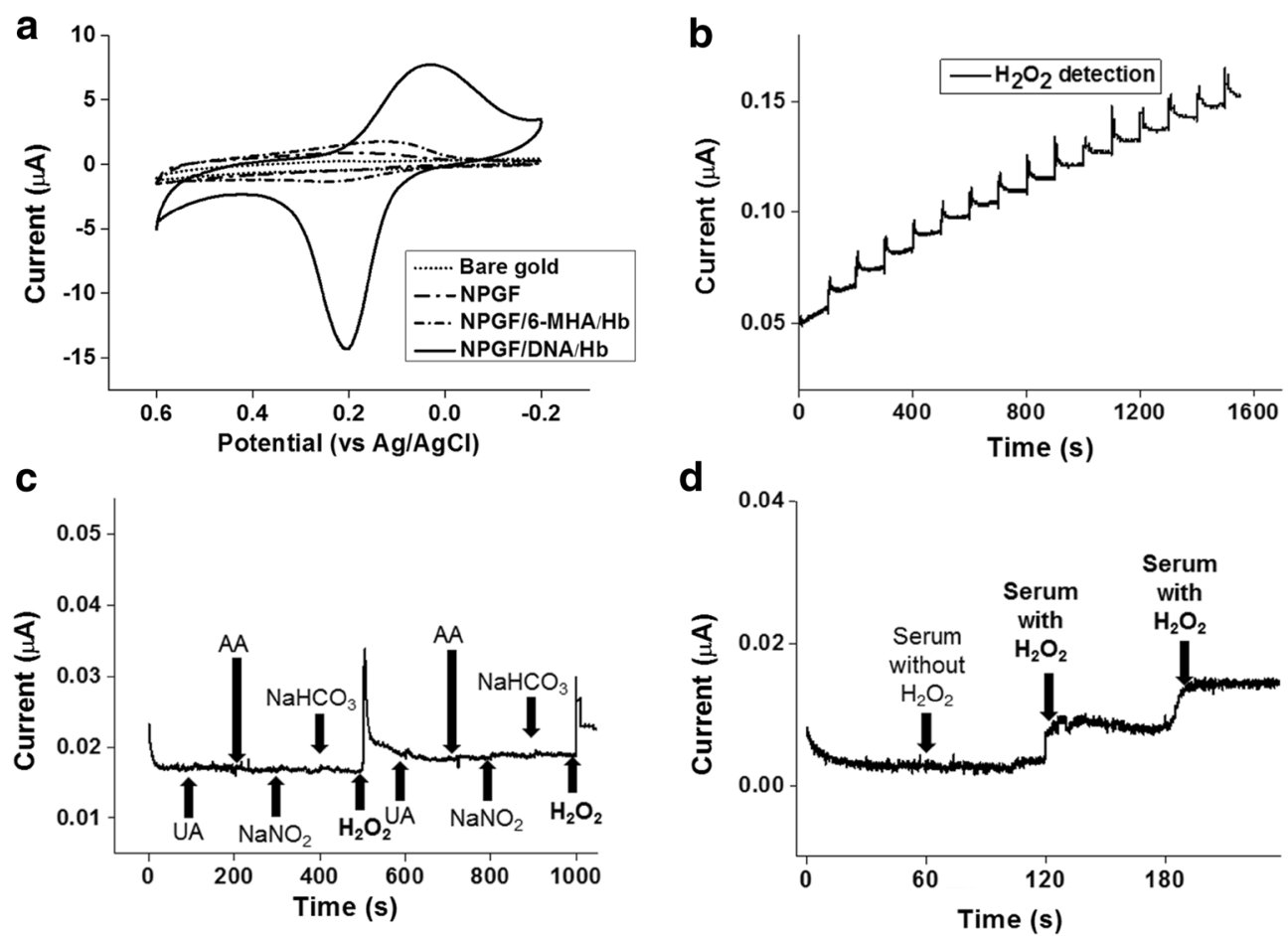

Fig. 4 a Cyclic voltammograms of Bare gold, NPGF electrode, NPGF/6-MHA/Hb, NPGF/DNA/Hb in PBS; amperometric i-t curves of $\mathbf{b}$ addition of $10 \mu \mathrm{L}$ of $100 \mu \mathrm{M} \mathrm{H}_{2} \mathrm{O}_{2}$ solution; c Successive addition of $1 \mu \mathrm{M} \cup \mathrm{A}, \mathrm{AA}, \mathrm{NaNO}_{2}, \mathrm{NaHCO}_{3}$, and $1 \mu \mathrm{M} \mathrm{H}_{2} \mathrm{O}_{2}$ solution; $\mathbf{d}$ successive addition of serum without $\mathrm{H}_{2} \mathrm{O}_{2}$ once and serum with $1 \mu \mathrm{M}$ of $\mathrm{H}_{2} \mathrm{O}_{2}$ twice

denatured or not at Additional file 1: Fig. S6. FT-IR spectroscopy is sensitive to the secondary structure of the protein. FT-IR analysis showed that $\mathrm{Hb}$ is not denatured after DNA hybridization to the cDNA. As widely known, the shapes of the amide I infrared absorbance bands of $\mathrm{Hb}$ provide specified information on the secondary structure of the polypeptide chain. The amide I band (1750$1650 \mathrm{~cm}^{-1}$ ) is caused by $\mathrm{C}=\mathrm{O}$ stretching vibrations of peptide linkages. In our result, the amide I band of $\mathrm{Hb}$ on the NPGF electrode was located at $1730.29 \mathrm{~cm}^{-1}$, and we verified $\mathrm{Hb}$ is not denatured.

\subsection{Detection of $\mathrm{H}_{2} \mathrm{O}_{2}$ by fabricated biosensor}

The amperometric $\mathrm{i}-\mathrm{t}$ curve was obtained for the $\mathrm{Hb}$ DNA conjugate on the NPGF electrode to measure the enzymatic reaction of the biosensor. The amperometric reaction of the biosensor was performed by continuous addition of $10 \mu \mathrm{L}$ of $100 \mu \mathrm{M} \mathrm{H}_{2} \mathrm{O}_{2}$ solution.

To achieve the complete reduction state of the $\mathrm{Hb}$ before the enzymatic reaction, $0.2 \mathrm{~V}$ was applied as the initial potential. The amperometric reaction curve for the enzymatic reaction of the biosensor during the addition of $\mathrm{H}_{2} \mathrm{O}_{2}$ is shown in Fig. 5. When $100 \mu \mathrm{M} \mathrm{H} \mathrm{H}_{2} \mathrm{O}_{2}$ solution was added every $100 \mathrm{~s}$, the reduction current of the biosensor was increased sharply with a steady amount of current (Fig. 4b).

To confirm the selectivity of the biosensor, $1 \mu \mathrm{M}$ of $\mathrm{UA}, \mathrm{AA}, \mathrm{NaNO}_{2}$ and $\mathrm{NaHCO}_{3}$ were added every $100 \mathrm{~s}$ subsequently to observe the response current of biosensor (Fig. 4c). In the only case of $1 \mu \mathrm{M} \mathrm{H}_{2} \mathrm{O}_{2}$ addition, the response current was increased compared to the results of UA, AA, $\mathrm{NaNO}_{2}$ and $\mathrm{NaHCO}_{3}$ addition.

The interferential experiment was conducted with real human blood serum sample. It was conducted to check interference when the proposed sensing platform is applied at in vivo. The ratio of serum was maintained as $6 \%$ of total volume just like the real human blood. After $60 \mathrm{~s}$ of signal stabilization, $10 \mu \mathrm{L}$ of serum without $\mathrm{H}_{2} \mathrm{O}_{2}$ was added to $5 \mathrm{~mL}$ of PBS electrolyte and showed no response current (Fig. 4d). To make clear, detection limit was confirmed as $250 \mathrm{nM}$ at analyte with serum at Additional file 1: Fig. S5. So serum was verified as noninterferential byproduct to detect hydrogen peroxide. $100 \mu \mathrm{M}$ of $\mathrm{H}_{2} \mathrm{O}_{2}$ solution were added twice after $60 \mathrm{~s}$ of stabilization, two stable response current were observed. These outstanding performance of our proposed sensor can be applied as a sensing platform in the field of in vivo biosensor at the future. 

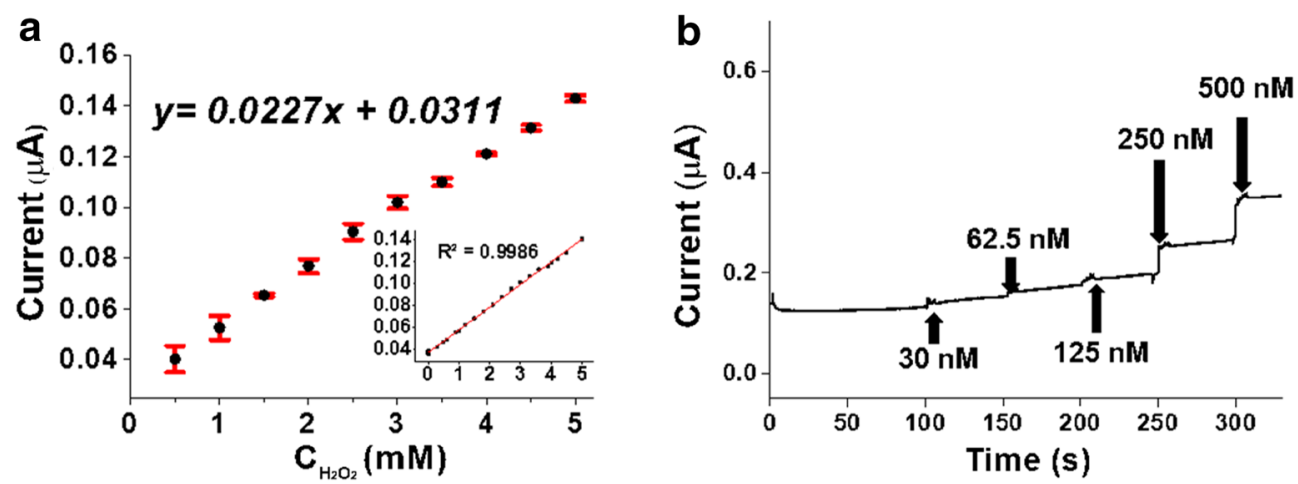

Fig. 5 a Calibration curve of $0.5 \mathrm{mM}$ concentration of $\mathrm{H}_{2} \mathrm{O}_{2}$ versus catalytic peak current and error bar with trend line equation and linear range (0.00025-5.0 mM) with a correlation coefficient of 0.9986; $\mathbf{b}$ amperometric response curves of Hb/DNA/NPGF addition of $30 \mathrm{nM}, 62.5 \mathrm{nM}, 125 \mathrm{nM}$, $250 \mathrm{nM}$ and $500 \mathrm{nM} \mathrm{H}_{2} \mathrm{O}_{2}$ solution

The reproducibility and repeatability of the proposed sensor was also studied by amperometric response with $1 \mathrm{mM} \mathrm{H}_{2} \mathrm{O}_{2}$ at PBS buffer solution. Additional file 1: Fig. S4 showed response current from three equally fabricated individual sensors. The relative standard deviation (R.S.D.) from three sensors showed 5.6\%. Also, one of uniformly fabricated sensor showed repeated response current at same concentration $\mathrm{H}_{2} \mathrm{O}_{2}$ during 10 successive addition and the R.S.D. showed $6.8 \%$. Also, from the trend line equation $(Y=0.0227 x+0.0311)$, we can assume that it showed wide linear range $(0.00025-$ $5.0 \mathrm{mM}$ ) with little error bar from three individually fabricated sensors with 10 measurements (Fig. 5a). From the results, we could conclude fabricated sensor showed similar performance respectively.

To test the detection limit of the biosensor, various concentrations of $\mathrm{H}_{2} \mathrm{O}_{2}(30,62.5,125,250$ and $500 \mathrm{nM})$ were added to the sensor (Fig. 5b). According to the amperometric results, the detection limit of the biosensor for $\mathrm{H}_{2} \mathrm{O}_{2}$ showed as $250 \mathrm{nM}$. And it also showed remarkable performance comparing other enzymatic sensors. So various types of $\mathrm{H}_{2} \mathrm{O}_{2}$ sensors were compared to prove the outstanding performance of our work (Additional file 1: Table S1).

\section{Conclusions}

In the present study, an electrochemical biosensor composed of Hb-DNA conjugate on the NPGF was fabricated for $\mathrm{H}_{2} \mathrm{O}_{2}$ detection with electrochemical signal enhancement and selectivity. The Hb-DNA conjugate was fabricated to immobilize the Hb-DNA conjugate uniformly onto the electrode without $\mathrm{Hb}$ aggregation. Furthermore, the NPGF electrode fabricated by electrodeposition technique was used to extend the surface area of the electrode for electrochemical signal enhancement. The fabricated Hb-DNA conjugate was verified by UV-VIS and SDS-PAGE. The fabrication of the NPGF electrode by electrodeposition was confirmed by SEM. The preparation of the biosensor by DNA hybridization was also investigated by $\mathrm{CV}$. This biosensor prepared with DNA and NPGF electrode showed the uniform orientation of sensing molecule on the electrode compared to electrode fabricated without DNA hybridization. The electrochemical properties of this biosensor showed the enhanced electrochemical signal compared to the conventional electrode prepared without NPGF electrode. Moreover, the proposed biosensor composed of Hb-DNA conjugate on the NPGF electrode showed selective amperometric response with selective performance for detecting $\mathrm{H}_{2} \mathrm{O}_{2}$ in mixtures added with $\mathrm{NaHCO}_{3}$ and AA. In the result, the proposed biosensor composed of Hb-DNA conjugate on the NPGF electrode can be used as a powerful sensing platform for biosensor development with electrochemical signal enhancement and high selectivity.

\section{Additional file}

Additional file 1: Figure S1. SEM images of electrodeposition under A) $-1.5 \mathrm{~V}$ and $30 \mathrm{~s} ; \mathrm{B})-1.3 \mathrm{~V}$ and $45 \mathrm{~s}$. Figure $\mathbf{S 2}$. Column diagram of the NPGF nanoparticle size with standard error values. Figure S3. Cyclic voltammograms of 1 st cycle and 25th cycle. Figure S4. Column diagram of three individually fabricated sensors with standard error values. Figure S5. Amperometric response curves of addition of $125 \mathrm{nM}, 250 \mathrm{nM}$ and $500 \mathrm{nM} \mathrm{H}_{2} \mathrm{O}_{2}$ solution with serum analyte. Figure S6. FT-IR analysis of A) NPGF/CDNA; B) NPGF/DNA/Hb. Table S1. Comparison of several $\mathrm{H}_{2} \mathrm{O}_{2}$ sensors.

\section{Abbreviations}

HRP: horseradish peroxidase; NPGF: nanoporous gold thin film; Sulfo-SMCC: sulfosuccinimidyl 4-cyclohexane-1-carboxylate; PEG: polyethylene glycol; TCEP: tris(2-carboxyethyl)phosphine; TE: tris-EDTA; DTT: dithiothreitol; 6-MHA: 
6-mercaptohexanoic acid; RA: roughness average; Rq: RMS roughness; Rmax: maximum roughness.

\section{Authors' contributions}

$\mathrm{JJ}$ and JY contributed to experiments. JY, TL and JYL contributed to conceptualization. JJ, HYC, TL and JWC discussed the experimental data. JY, HYC and JWC contributed to revise manuscript. JWC directed entire research. All authors read and approved the final manuscript.

\section{Author details}

${ }^{1}$ Department of Chemical and Biomolecular Engineering, Sogang University, 35 Baekbeom-ro (Sinsu-dong), Mapo-gu, Seoul 121-742, Republic of Korea. ${ }^{2}$ Department of Chemical Engineering, Kwangwoon University, 20 Kwangwoon-ro, Nowon-gu, Seoul 01897, Republic of Korea. ${ }^{3}$ Department of Chemistry and Chemical Biology, Rutgers, The State University of New Jersey, Piscataway, NJ 08854, USA

\section{Acknowledgements}

This research was supported by the Leading Foreign Research Institute Recruitment Program, through the National Research Foundation of Korea (NRF), funded by the Ministry of Science, ICT and Future Planning (MSIP) (2013K1A4A3055268) and Basic Science Research Program through the National Research Foundation of Korea (NRF) funded by the Ministry of Education (2016R1A6A1A03012845)

\section{Competing interests}

The authors declare that they have no competing interests.

\section{Availability of data and materials}

The authors have no data to share since all data are shown in the submitted manuscript.

\section{Funding}

This research was supported by the Leading Foreign Research Institute Recruitment Program, through the National Research Foundation of Korea (NRF), funded by the Ministry of Science, ICT and Future Planning (MSIP) (2013K1A4A3055268) and Basic Science Research Program through the National Research Foundation of Korea (NRF) funded by the Ministry of Education (2016R1A6A1A03012845).

\section{Publisher's Note}

Springer Nature remains neutral with regard to jurisdictional claims in published maps and institutional affiliations.

Received: 2 November 2018 Accepted: 24 December 2018

Published online: 03 January 2019

\section{References}

1. P.N. Bartlett, Bioelectrochemistry: fundamentals, experimental techniques and applications, 1st edn. (John Wiley \& Sons Inc, West Sussex, 2008), pp. $27-42$
2. A. Messerschmidt, R. Huber, T. Poulos, K. Wieghardt, Handbook of metalloproteins, 1st edn. (John Wiley \& Sons Inc, West Sussex, 2001), pp. 351-362

3. I. Bertini, A. Sigel, H. Sigel, Handbook on metalloproteins, 1st edn. (CRC Press, Boca Raton, 2001), pp. 428-439

4. M.L. Kennedy, B.R. Gibney, Curr. Opin. Struct. Biol. 11, 485-490 (2001)

5. R.H. Holm, P. Kennepohl, E.I. Solomon, Chem. Rev. 96, 2239-2314 (1996)

6. Y. Du, X.L. Luo, J.J. Xu, H.Y. Chen, Bioelectrochemistry 70, 342-347 (2007)

7. X. Wang, Z. You, H. Sha, Z. Sun, W. Sun, J. Solid State Electrochem. 18, 207-213 (2014)

8. A.K. Yagati, T. Lee, J. Min, J.-W. Choi, Biosens. Bioelectron. 47, 385-390 (2013)

9. A.K. Yagati, T. Lee, J. Min, J.-W. Choi, Bioelectrochemistry 80, 169-174 (2011)

10. R.P. Singh, D.Y. Kang, B.K. Oh, J.-W. Choi, Biotechnol. Bioprocess. Eng. 14, 443-449 (2009)

11. G.P. Bienert, J.K. Schjoerring, T.P. Jahn, Biochim. Biophys. Acta - Biomembr. 1758, 994-1003 (2006)

12. A. Hernández-Barrera, A. Velarde-Buendía, I. Zepeda, F. Saechez, C. Quinto, R. Sánchez-Lopez, A.Y. Cheung, H.-M. Wu, L. Cardenas, Sensors 15 855-867 (2015)

13. N.H. Al-Hardan, M.A.A. Hamid, R. Shamsudin, N.K. Othman, L.K. Keng, Sensors 16, $1004(2016)$

14. S.S. Razola, B.L. Ruiz, N.M. Diez, H.B. Mark, J.M. Kauffmann, Biosens. Bioelectron. 17, 921-928 (2002)

15. A. Zhu, Y. Tian, H. Liu, Y. Luo, Biomaterials 30, 3183-3188 (2009)

16. E. Reimhult, F. Höök, Sensors 15, 1635-1675 (2015)

17. W.A. El-Said, J.-H. Lee, B.-K. Oh, J.-W. Choi, Electrochem. Commun. 12, 1756-1759 (2010)

18. J. Moser, S. Punchihewa, P.P. Infelta, M. Gratzel, Langmuir 7, 3012-3018 (1991)

19. R. Levicky, T.M. Herne, M.J. Tarlov, S.K. Satija, J. Am. Chem. Soc. 120 9787-9792 (1998)

20. L. Wang, Y. Sun, A. Li, G. Wei, Materials 9, 53 (2016)

21. T. Lee, A.K. Yagati, J. Min, J.-W. Choi, Adv. Funct. Mater. 24, 1781-1789 (2014)

22. T. Lee, A.K. Yagati, F. Pi, A. Sharma, J.-W. Choi, P. Guo, ACS Nano 9 6675-6682 (2015)

23. T. Lee, S.U. Kim, J. Min, J.-W. Choi, Adv. Mater. 22, 510-514 (2010)

24. J. Yoon, Y.-H. Chung, T. Lee, J.H. Kim, J. Kim, J.-W. Choi, Colloids Surf. B 136, 853-858 (2015)

25. M. Sirajuddin, S. Ali, A. Badshah, J. Photochem. Photobiol. B Biol. 124, $1-19(2013)$

26. H.-Y. Gu, A.-M. Yu, H.-Y. Chen, J. Electroanal. Chem. 516, 119-126 (2001)

27. M.J. Gira, K.P. Tkacz, J.R. Hampton, Nano Converg. 3, 6 (2016)

28. G.Y. Kim, J. Kim, W. Jo, D.-H. Son, D.-H. Kim, J.-K. Kang, Nano Converg. 1, 27 (2014)

29. R.J. Toh, W.K. Peng, J. Han, M. Pumera, Sci. Rep. 4, 6209 (2014)

\section{Submit your manuscript to a SpringerOpen ${ }^{\circ}$ journal and benefit from:}

- Convenient online submission

- Rigorous peer review

- Open access: articles freely available online

- High visibility within the field

- Retaining the copyright to your article

Submit your next manuscript at $\boldsymbol{\nabla}$ springeropen.com 